\title{
Effects of Antioxidants Vitamin E and C on ErythrocyteFragility, HaemoglobinIndex and Colonic Temperature of Transported Japanese Quails (Coturnixcoturnix japonica)
}

\section{Ndazo Salka Minka* and Joseph Olusegun Ayo ${ }^{2}$}

${ }^{1}$ College of Agriculture and Animal Science, P.M.B. 2134, Department of Animal Health and Husbandry,Division of Agricultural Colleges, Ahmadu Bello University, Mando - Kaduna, Nigeria

${ }^{2}$ Department of Physiology, Faculty of Veterinary Medicine, Ahmadu Bello University, Zaria, Nigeria

\begin{abstract}
The present study investigated the effects of antioxidants Vitamin $E(V E)$ and $C$ (ascorbic acid, AA) on erythrocytes osmotic fragility (EOF), haemoglobin index $(\mathrm{HI})$, colonic temperature $(\mathrm{CT})$ and recovery times of transported Japanese quails during the hot-dry conditions. Two hundred male Japanese quails were used. The birds were randomly and equally divided into four groups: VE and AA groups, administered with $0.5 \mathrm{mg} / \mathrm{kg}$ and $200 \mathrm{mg} /$ $\mathrm{kg}$ body weight of VE and AA, respectively, control transported group (control group), administered with $0.5 \mathrm{ml}$ of sterile water, and sedentary non-transported group (S). One hour after the administration of the antioxidants, the birds were transported by road for $2 \mathrm{~h}$. The EOF, $\mathrm{Hl}$ and CT were recorded before transportation, immediately after transportation ( 0 ) and on $3^{\text {rd }}$ and $7^{\text {th }}$ day of post-transportation period. The results showed that transportation induced hyperthermia, increased EOF and hypochromic erythrocytes in the quails, the effects of which were mitigated by antioxidants VE and AA. Base-line values for EOF were returned to normal in the control, AA and VE quails on days 7,3 and 0 , respectively post-transportation. The findings showed that recovery time after transportation in quails should be 7 days; but the duration may be reduced to 3 days if treated with AA or eliminated completely if the quails are treated with VE before transportation. The ameliorating effect was more pronounced in quails administered with antioxidant VE. The EOF may be employed as a biomarker and additional diagnostic tool for the assessment of transport-induce oxidative stress in quails.
\end{abstract}

Keywords: Antioxidant;Ascorbic acid; Colonic temperature; Erythrocyte fragility; Oxidative stress; Quails; Road transportation; Vitamin E

\section{Introduction}

The increase in demand for Japanese quails (Coturnixcoturnix japonica) as laboratory and farm birds has necessitated their transportation from one laboratory or farm to the other for the purpose of research, meat and egg production. Transportation of quails by road may compromise their welfare, productivity and the expected experimental results, especially if it is done under adverse environmental conditions and the birds are not given adequate time for the normalization of potentially confounding physiological changes.

Road transportation of animals under high environmental temperature induces physiological and psychological stress which may cause damages to enzymatic and non-enzymatic antioxidant defense systems. The stress stimulates excessive production of stress hormones, acute phase protein and reactive oxygen species (ROS), including superoxide anion radicals, hydroxyl radical, hydrogen peroxide and singlet oxygen [1-6]. The ROS readily oxidise and damage essential biological molecules and increase the susceptibility of the body to diseases. The red blood cells (RBCs) are highly susceptible to oxidative stress as a result of high contents of oxygen and unsaturated fatty acids in their membranes [1,7]. The oxidation of RBCs has been used as a model system for the investigation of oxidative damage of biomembranes [8]. The EOF is a measure of the erythrocyte overall response to osmotic pressure, and is influenced by several extrinsic and intrinsic factors [9]. The EOF has been found to alter in various pathological conditions. The integrity of the RBCs may be determined by measuring the changes in EOF. Measurement of EOF has been applied to the diagnosis of haemolytic diseases, diabetes mellitus and studies of membrane permeability, as an important indicator of haemolysis in blood vessels
$[7,10]$.The use of EOF as a biomarker of road transport-induced stress in livestock is a new field of study that may add to the arsenals of tests, currently used in the diagnosis of stress due to road transportation [11-13]. Body temperature measurement is an important method of evaluation of physiological status. It is also an ideal indicator for the assessment of stress and adaptability of livestock, including poultry, to various environmental stress factors [14-16].

Several stress factors have been reported to decrease the level of body antioxidants, vitamin $\mathrm{E}(\mathrm{VE})$ and vitamin $\mathrm{C}$, otherwise known as ascorbic acid (AA); resulting in increases in the body requirements in these vitamins [14,17-19]. The administration of the vitamins exerts ameliorating effects which are well manifested; when the body AA and VE are either overwhelmed or exhausted as a result of increased ROS generation by stress factors that overtax the animal control systems $[18,20]$. Therefore, a decrease in the concentration of antioxidant vitamins causes an increase in lipid peroxidation in the plasma and tissues, leading to damage of cell membranes $[21,22]$.

*Corresponding author: NS Minka, College of Agriculture and Animal Science, P.M.B. 2134, Department of Animal Health and Husbandry, Division of Agricultural Colleges, Ahmadu Bello University, Mando-Kaduna, Nigeria, Tel: +2348036527538; E-mail:mnsalka@yahoo.com

Received October 25, 2013; Accepted December 18, 2013; Published December 22, 2013

Citation: Minka NS, Ayo JO (2013) Effects of Antioxidants Vitamin E and C on ErythrocyteFragility, HaemoglobinIndex and Colonic Temperature of Transported Japanese Quails (Coturnixcoturnix japonica). J Veterinar Sci Technol 4: 149. doi:10.4172/2157-7579.1000149

Copyright: ( 2013 Minka NS, et al. This is an open-access article distributed under the terms of the Creative Commons Attribution License, which permits unrestricted use, distribution, and reproduction in any medium, provided the original author and source are credited. 
Citation: Minka NS, Ayo JO (2013) Effects of Antioxidants Vitamin E and C on ErythrocyteFragility, HaemoglobinIndex and Colonic Temperature of Transported Japanese Quails (Coturnixcoturnix japonica). J Veterinar Sci Technol 4: 149. doi:10.4172/2157-7579.1000149

Page 2 of 8

Previous reports have revealed the beneficial effects of supplementation of VE and AA on birds and animals, subjected to various oxidative stress factors $[12,16,18,22]$.Several studies have evaluated the responses of poultry birds to transportation stress [12,15,23-25]. Inspite of the increasing demand for quails worldwide as laboratory and farm birds, the response and tolerance of the body temperature and erythrocytes of quails to road transportation under unfavorable environmental conditions are poorly studied $[2,16,26]$. There is paucity of information in the available literature on the ameliorating effects of antioxidant vitamins on EOF and Colonic Temperature (CT), responses of quails to stress due to road transportation under incremental environmental conditions. Furthermore, the duration of recovery time required for the RBCs and CT of quails to return to normal after exposure to transport-induced oxidative stress is yet to be established.

The aims of the present study were to investigate the ameliorating effects of antioxidants VE and AA on EOF, haemoglobin index and $\mathrm{CT}$ in quails transported by road during the hot-dry conditions, and determines the duration of post-transportation recovery time.

\section{Materials and Methods}

\section{Study area and thermal environmental data}

The study was carried out in Livestock Farm of the College of Agriculture and Animal Science, Ahmadu Bello University, Kaduna $\left(11^{\circ} 10^{\prime} \mathrm{N}, 07^{\circ} 38^{\prime} \mathrm{E}\right)$, located in the NorthernGuinea Savannah zone of Nigeria, in March 2012 during the hot-dry conditions.Ambient temperature (AT) and relative humidity (RH) inside the penwere recorded at 07:00 $\mathrm{h}, 13: 00 \mathrm{~h}$ and 18:00 $\mathrm{h}$ daily before transportation and thereafter seven consecutive days using a wet- and dry-bulb thermometer (DTH 1, Clarke Int. Epping, Essex, UK), placed near the centre of the pen a little (about $50 \mathrm{~cm}$ ) above the heads of the birds. The AT and $\mathrm{RH}$ were also recorded in the vehicle at $30 \mathrm{~min}, 1 \mathrm{~h}$ and $2 \mathrm{~h}$ of the transportation period. Temperature-humidity index (THI) was recorded as a measure of thermal load on the birds during the transportation. THI is determined by equation from the RH and the air temperature and is calculated as described by Steadman [27]. The principle of THI impact on livestock is based on the fact that as the $\mathrm{RH}$ at any AT increases, it becomes progressively more difficult for the animal to cool itself.

\section{Colonic temperature}

The colonic temperature (CT)was recorded in 50 quails, selected at random, and $\mathrm{AT}$ and $\mathrm{RH}$ were measured concurrently for three consecutive days before the transportation in order to obtain baseline data. The measurements were also carried out on sedentary and transported birds during the journey at $30 \mathrm{~min}, 1 \mathrm{~h}$ and $2 \mathrm{~h}$ of the transportation period, and at $4 \mathrm{~h}$ after the transportation. Thereafter, the recordings were done daily for the next 7 days after the transportation. The recording of CT was done by a digital clinical thermometer (Cocet, Shenzhen=Guangdong, China), inserted about $2-3 \mathrm{~cm}$ into the cloacae through the anus till an alarm sound was heard, indicating the end of the reading $[12,16]$.

\section{Birds and management}

From a total number of 500 quails, raised in deep litter from dayold to maturity in a standard pen, 200 clinically healthy, matured male Japanese quails, aged 8 weeks and weighing between 181-190.0 g, selected by simple randomization, were used. The 200 quails were housed in a floor space area of $145 \mathrm{~cm} / \mathrm{bird}$; and provided with feeder and water through spaces of $1.30 \mathrm{~cm}$ and $0.6 \mathrm{~cm}$, respectively.
Supplementary lighting was not provided, but the birds had 9-11 h of natural lighting per day, characteristic of the daytime lighting period in the Northern Guinea Savannah zone of Nigeria during the hotdry season. The nutrient content of the diet fed to the matured birds consisted of, among others, approximately $25 \%$ protein, about 12.6 mega joules (MJ) of metabolized energy (ME) per kilogram, $1.0 \%$ calcium, minerals and antioxidant vitamins like vitamin $\mathrm{E}-4,000 \mathrm{IU}$, vitamin C - $60 \mathrm{mg}$, vitamin A - $7812.5 \mathrm{IU}$, Vitamin $\mathrm{B}_{6}-2.2 \mathrm{mg}$, and selenium - $0.2 \mathrm{mg}$ per $\mathrm{kg}$ of feed. Clean drinking water was provided ad libitum.

\section{Experimental protocol and transportation of birds}

On transportation day, the birds were randomly assigned into four groups viz: vitamins $\mathrm{E}$ (VE), ascorbic acid (AA), control transported and sedentary (not transported) quails, each group consisting of 50 birds. Birds in each group were colour-marked for easy identification. Feed and water were withdrawn from the birds 6 hours before transportation. One hour before loading into a vehicle, 50 quails in VE and AA groups were administered orally and individually with VE and AA at doses of $0.5 \mathrm{mg} / \mathrm{kg}$ and $200 \mathrm{mg} / \mathrm{kg}$ body weight, respectively, dissolved in $1 \mathrm{ml}$ of sterile water. Control-transported (control) and sedentary (S) quails were given equivalent of sterile water. Thereafter, the birds were loaded in each of the three standard quail crates at a stocking density of about $130 \mathrm{~cm}^{2} /$ bird [28]. For transported crates each crate contained 18 birds from VE and AA quails and 14 control quails. This arrangement was provided in order to ensure the same transportation conditions for all the birds. Each crate used for the transportation was then loaded to a Golf-wagon vehicle (VW Automobile Com., Stuttgart, Germany) and transported for $2 \mathrm{~h}$. All the birds were transported at the same time on a typical asphalt single-lane road, from Kaduna $\left(11^{\circ} 10^{\prime} \mathrm{N}, 07^{\circ} 38^{\prime} \mathrm{E}\right)$ to Birnin Gwari $\left(11^{\circ} 40^{\prime} \mathrm{N}, 06^{\circ} 32^{\prime} \mathrm{E}\right)$ and from Birnin Gwari back to Kaduna, covering a distance of about $140 \mathrm{~km}$ with an average speed of $65 \mathrm{~km} / \mathrm{h}$. The sedentary quails were kept in a laboratory under thermoneutral AT $\left({ }^{\circ} \mathrm{C}\right)$ and $\mathrm{RH}(\%)$ during the $2 \mathrm{~h}$ of transportation period. The journey commenced by 11:00 $\mathrm{h}$ and was terminated at 13:00 h, similar to normal commercial practice in the study zone. After the transportation, all the birds were unloaded and returned to the same litter pen and offered the same conditions as it was done before transportation. Ten birds selected at random from each group were sacrificed before loading and administration of antioxidants to obtain base-line values of EOF. Immediately after transportation and on the $3^{\text {rd }}$ and $7^{\text {th }}$ day of post-transportation period, 10 birds from each group at each period were sacrificed for the determination of the effects of transportation and antioxidant supplementation on EOF.

\section{Blood sampling and measurement of erythrocyte osmotic fragility}

At each period that the quails were sacrificed, about 3-5 $\mathrm{ml}$ of blood was collected from each quail into a sterile test tube containing an anticoagulant. The blood samples were quickly kept on ice pack in a flask and taken immediately to the laboratory for the determinations of EOF, PCV, erythrocyte count and haemoglobin concentration. The EOF was determined as described by Beutler [29]. Briefly, $10 \mu \mathrm{l}$ of blood sample collected from each quail was added to tubes with increasing concentrations of buffered-saline solution $(\mathrm{pH} 7.4 ; 0,0.1$, $0.2,0.3,0.4,0.5,0.6,0.7,0.8,0.9 \%$ of $\mathrm{NaCl}$ ). The tubes were incubated at room temperature at $26^{\circ} \mathrm{C}$ for $30 \mathrm{~min}$ after mixing the blood gently. Thereafter, the samples were centrifuged at $150 \times \mathrm{g}$ for $10 \mathrm{~min}$ and the supernatant was collected. A spectrophotometer (Shimadzu UV160U UV-VIS, Shimadzu Corp, Kyoto, Japan) was used to determine the 
Citation: Minka NS, Ayo JO (2013) Effects of Antioxidants Vitamin E and C on ErythrocyteFragility, HaemoglobinIndex and Colonic Temperature of Transported Japanese Quails (Coturnixcoturnix japonica). J Veterinar Sci Technol 4: 149. doi:10.4172/2157-7579.1000149

Page 3 of 8

optical density of the supernatant at $540 \mathrm{~nm}$. Haemolysis in each tube was expressed as a percentage, taking $100 \%$ as the maximum value of the absorbance of the distilled water $(0 \% \mathrm{NaCl}$ concentration).

The EOF curve was obtained by plotting percentage haemolysis against the saline concentrations. Saline concentrations at 20\%, 50\% and $80 \%$ of haemolysis were used to represent the important segments of the curve [30].

From each blood sample, analysis for erythrocyte count, haemoglobin $(\mathrm{Hb})$ concentration and PCV were done as described by Schalmet al. [31]. The following haematimetric (intrinsic) indices were calculated: mean corpuscular volume (MCV: PCV x10/erythrocytes), mean corpuscular haemoglobin concentration (MCHC: Hbx100/ $\mathrm{PCV}$ ), mean corpuscular haemoglobin (MCH: Hbx10/erythrocytes) and haemoglobin index (HI) (obtained Hbxaverage erythrocytes/ average Hbxobtained erythrocytes) [31,32].

\section{Statistical analysis}

Data obtained were subjected to Student's $t$-test and were expressed as mean \pm standard error of the mean (Mean \pm SEM). Repeatedmeasures ANOV A was employed to determine the effects of sampling time, differences between groups and interactions between time $\mathrm{x}$ treatments followed by Turkey's post-hoc comparison test. Values of $\mathrm{P}<0.05$ were considered significant. The EOF results were expressed in simple percentages.

\section{Results}

\section{Environmental data}

The thermal environmental data recorded before, during and after transportation periods showed that the AT, RH and THI recorded inside the pen before and after transportation had mean values of $37.0 \pm$ $0.5^{\circ} \mathrm{C}, 72.7 \pm 5.0 \%$ and $32 \pm 3.0$, respectively. During the transportation period, the thermal environmental conditions, recorded inside the vehicle fluctuated between 29.5 and $37.6^{\circ} \mathrm{C}$ for $\mathrm{AT}$, from $56.6 \%$ to $74.7 \%$ for RH and 39 to 42 for THI. Overall, the mean values for AT, RH and THI, recorded during the transportation period were $32.5 \pm 1.4^{\circ} \mathrm{C}, 66.9$ $\pm 5.7 \%$, and $40.4 \pm 6.7$, respectively.

\section{Colonic temperature}

The CT of the quails recorded before transportation had mean, maximum and minimum values of $40.4 \pm 0.2^{\circ} \mathrm{C}, 41.7^{\circ} \mathrm{C}$ and $39.0^{\circ} \mathrm{C}$, respectively. The $\mathrm{CT}$ value recorded at $18: 00 \mathrm{~h}$ was significantly $(\mathrm{P}<0.05)$ higher than that recorded at either 07:00 $\mathrm{h}$ or 14:00 h.The birds also exhibited individual variation in CT. The mean CT recorded in all the groups of the quails during transportation period are shown in Table

\begin{tabular}{|c|c|c|c|c|}
\hline \multicolumn{5}{|c|}{ Group of quails } \\
\hline Journey time & $\begin{array}{c}\text { VE } \\
(n=40)\end{array}$ & $\begin{array}{c}\text { AA } \\
(n=40)\end{array}$ & $\begin{array}{l}\text { Control } \\
(n=40)\end{array}$ & $\begin{array}{l}\text { Sedentary } \\
(n=40)\end{array}$ \\
\hline Pre-transportation ${ }^{x}$ & $40.8 \pm 0.5$ & $40.4 \pm 0.2$ & $40.6 \pm 0.2$ & $40.8 \pm 0.1$ \\
\hline $30 \mathrm{~min}$ & $41.0 \pm 0.3$ & $42.0 \pm 0.3$ & $42.6 \pm 0.6$ & $40.7 \pm 0.2$ \\
\hline $1 \mathrm{~h}$ & $40.5 \pm 0.2$ & $41.7 \pm 0.3$ & $42.5 \pm 0.8$ & $40.8 \pm 0.3$ \\
\hline $2 \mathrm{~h}$ & $40.6 \pm 0.1$ & $41.2 \pm 0.5$ & $42.4 \pm 0.2$ & $41.0 \pm 0.2$ \\
\hline Mean \pm SEM & $40.7 \pm 0.2^{\mathrm{a}}$ & $41.3 \pm 0.6^{b}$ & $42.5 \pm 0.4^{\mathrm{c}}$ & $40.8 \pm 0.4^{a}$ \\
\hline$\Delta \mathrm{CT}$ & -0.1 & 0.8 & 1.8 & 0.0 \\
\hline
\end{tabular}

Mean values with different superscripts within a row differ significantly $(P<0.05)$. Note: $\Delta \mathrm{CT}=\mathrm{CT}$ at $2 \mathrm{~h}-\mathrm{CT}$ at pre-transportation; $\mathrm{x}=$ not included in calculation of mean values.

Table 1: Colonic temperature $\left({ }^{\circ} \mathrm{C}\right)$ responses of quails to 2-h transportation and administration of vitamin $\mathrm{E}$ and ascorbic acid.

\begin{tabular}{|c|c|c|c|c|}
\hline \multicolumn{5}{|c|}{ Group of quails } \\
\hline Recovery time & $\operatorname{VE}(n=10)$ & AA $(n=10)$ & $\begin{array}{l}\text { Control } \\
(n=10)\end{array}$ & $\begin{array}{l}\text { Sedentary } \\
\quad(n=10)\end{array}$ \\
\hline $1 \mathrm{~h}$ after journey & $41.6 \pm 0.2$ & $41.8 \pm 0.4$ & $42.6 \pm 0.6$ & $41.4 \pm 0.4$ \\
\hline $2 \mathrm{~h}$ & $41.2 \pm 0.3$ & $41.0 \pm 0.7$ & $42.2 \pm 0.5$ & $41.4 \pm 0.1$ \\
\hline $3 \mathrm{~h}$ & $40.4 \pm 0.6$ & $41.6 \pm 0.2$ & $41.4 \pm 0.6$ & $40.4 \pm 0.6$ \\
\hline $4 \mathrm{~h}$ & $40.6 \pm 0.2$ & $40.6 \pm 0.2$ & $42.0 \pm 0.4$ & $40.8 \pm 0.1$ \\
\hline Mean \pm SEM & $41.0 \pm 0.2^{\mathrm{a}}$ & $41.3 \pm 0.5^{\mathrm{a}}$ & $42.1 \pm 0.7^{\mathrm{b}}$ & $41.0 \pm 0.5^{\mathrm{a}}$ \\
\hline Day 1 after journey & $40.6 \pm 0.1$ & $40.4 \pm 0.1$ & $41.4 \pm 0.5$ & $40.4 \pm 0.1$ \\
\hline Day 3 & $40.5 \pm 0.2$ & $40.7 \pm 0.1$ & $40.7 \pm 0.7$ & $40.3 \pm 0.2$ \\
\hline Day 7 & $40.7 \pm 0.6$ & $40.3 \pm 0.4$ & $40.4 \pm 0.6$ & $40.4 \pm 0.5$ \\
\hline Mean \pm SEM & $40.6 \pm 0.2^{\mathrm{ns}}$ & $40.5 \pm 0.5^{\text {ns }}$ & $40.7 \pm 0.5^{\mathrm{ns}}$ & $40.4 \pm 0.5^{\mathrm{ns}}$ \\
\hline
\end{tabular}

Mean values with different superscripts within a row differ significantly $(P<0.05)$. ns= non-significant $(P>0.05)$

Table 2: Colonic temperature $\left({ }^{\circ} \mathrm{C}\right)$ responses of transported quails pretreated with antioxidants vitamin $\mathrm{E}$ and ascorbic acid during the first $4 \mathrm{~h}$ and 7 days of posttransportation recovery periods.

1.The $\mathrm{CT}$ values recorded in VE and AA quails at $30 \mathrm{~min}, 1 \mathrm{~h}$ and $2 \mathrm{~h}$ of the transportation period were significantly lower $(\mathrm{P}<0.05)$ than the corresponding values recorded in control quails. The mean $\mathrm{CT}$ value of $40.7 \pm 0.2^{\circ} \mathrm{C}$ recorded in VE quails was significantly lower $(\mathrm{P}<0.001)$ than the corresponding values of $41.3 \pm 0.6^{\circ} \mathrm{C}, 42.5 \pm 0.4^{\circ} \mathrm{C}$ and 40.8 $\pm 0.4^{\circ} \mathrm{C}$, recorded in $\mathrm{AA}$, control and sedentary quails, respectively during the transportation period. Furthermore, the differential value $(\Delta \mathrm{CT})$, which is a magnitude of change in thermoregulatory response to thermal stress, of $-0.1^{\circ} \mathrm{C}$, recorded in VE quails was significantly lower $(\mathrm{P}<0.001)$ than the corresponding $\Delta \mathrm{CT}$ values of $0.8^{\circ} \mathrm{C}, 1.8^{\circ} \mathrm{C}$ and $0.0^{\circ} \mathrm{C}$ recorded in $\mathrm{AA}$, control and sedentary quails, respectively immediately after the transportation period (Table 1). Four hours after transportation and feeding, the CT of sedentary, VE and AA quails returned to base-line values; while the $\mathrm{CT}$ obtained in control quails were significantly higher $(\mathrm{P}<0.05)$ than the base-line values. However a day after the transportation, the $\mathrm{CT}$ of the control-transported quails, although still higher, also returned to base-line (Table 2).

\section{Erythrocyte count, haemoglobin and intrinsic parameters}

In $\mathrm{VE}$ and $\mathrm{AA}$ quails, transportation increased the erythrocytes count, $\mathrm{Hb}$ concentration, $\mathrm{PCV}$ and $\mathrm{MCHC}$ and decreased intrinsic parameters of $\mathrm{MCV}, \mathrm{MCH}$ and HI.However, the changes in these values were not significantly $(\mathrm{P}>0.05)$ different from the pre-transportation range values of $3,0-3.6 \times 10^{6} / \mathrm{ul}, 16.8-18.2 \mathrm{~g} / \mathrm{l}, 38.9-40.5 \%, 32.2-33.9 \mathrm{~g} /$ dl, 130-136fl, 40.5-44.5pg and 0.94-0.97recorded for erythrocytes, $\mathrm{Hb}$, PCV, MCHC, MCV, MCH and HI, respectively. In controlquails the values recorded post-transportation were significantly higher $(\mathrm{P}<0.05)$ than the pre-transportation and the corresponding values recorded in VE and AA quails. The $\mathrm{Hb}$ index recorded in control quails posttransportation had the value of 0.79 which was maintained up to the $7^{\text {th }}$ day of recovery period, while in $\mathrm{VE}, \mathrm{AA}$, and sedentary quails the index was between 0.92-0.97.

\section{Erythrocyte osmotic fragility}

Figure 1 shows the pre-transportation EOF of the quails. The median (50\%), minimum (20\%) and maximum (80\%) corpuscular fragility occurred at $0.4,0.45$ and $0.32 \% \mathrm{NaCl}$ concentration, respectively; and the difference in the values was not significant $(\mathrm{P}>0.05)$ between the groups (Figure 1). The EOF recorded immediately after transportation and on the $3^{\text {rd }}$ and $7^{\text {th }}$ day post-transportation periods are shown in Figures 2, 3 and 4.The mean, minimum and maximum corpuscular fragility values recorded in VE quails immediately after transportation were $0.42,0.45$ and $0.38 \% \mathrm{NaCl}$ concentration, respectively, and the 
Citation: Minka NS, Ayo JO (2013) Effects of Antioxidants Vitamin E and C on ErythrocyteFragility, HaemoglobinIndex and Colonic Temperature of Transported Japanese Quails (Coturnixcoturnix japonica). J Veterinar Sci Technol 4: 149. doi:10.4172/2157-7579.1000149

values though higherthan pre-transportation and sedentary values, were not significantly $(\mathrm{P}>0.05)$ different. Similarly, 3 and 7 days after the transportation, the EOF values in VE quails were not statistically different $(\mathrm{P}>0.05)$ from pre-transportation values. However, the values were lower $(\mathrm{P}<0.001)$ than the corresponding values obtained

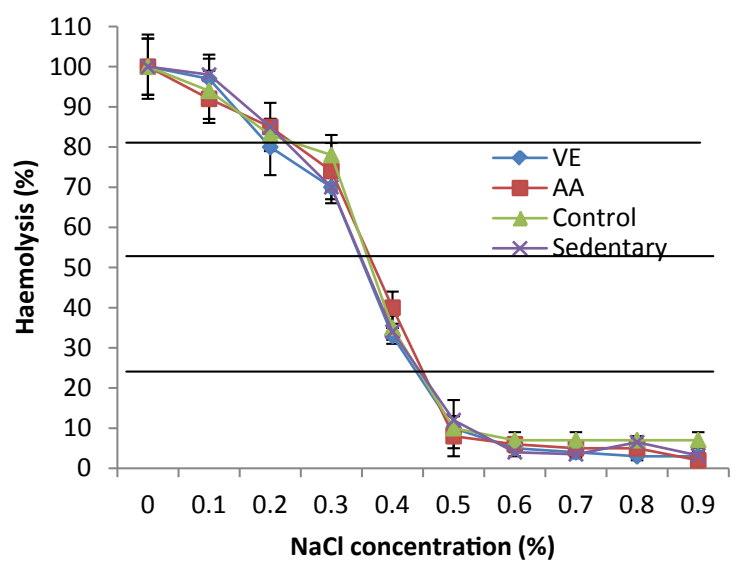

Figure 1: Erythrocyte osmotic fragility of quails before transportation by road.

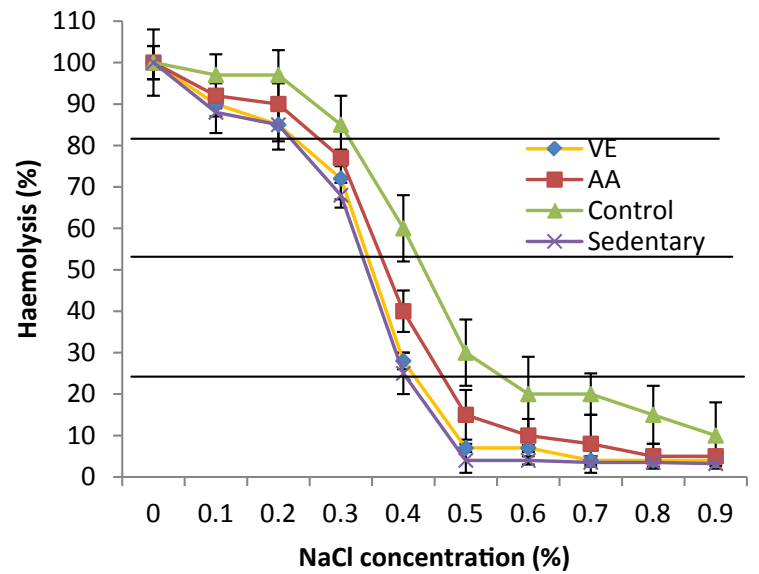

Figure 2: Erythrocyte osmotic fragility of quails administered with vitamin $E$ and ascorbic acid immediately after road transportation.

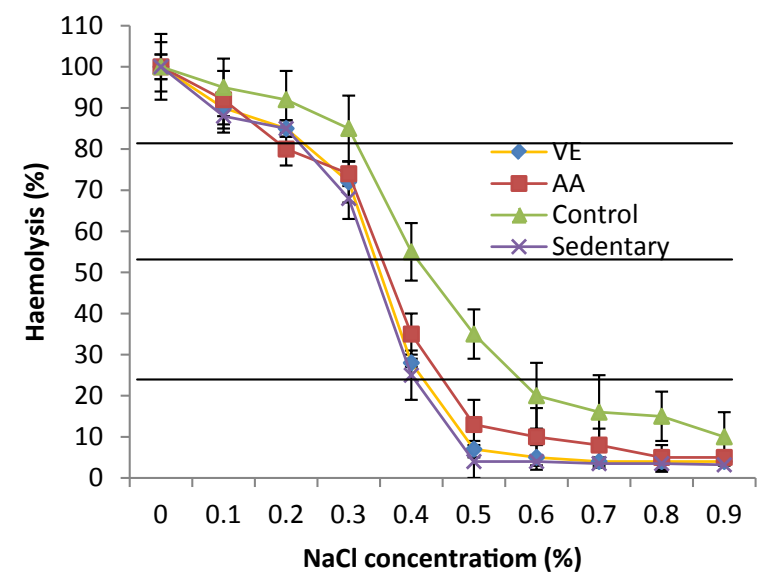

Figure 3: Effects of antioxidants vitamin $E$ and ascorbic acid on erythrocyte osmotic fragility of quails on day 3 of post-transportation recovery period.

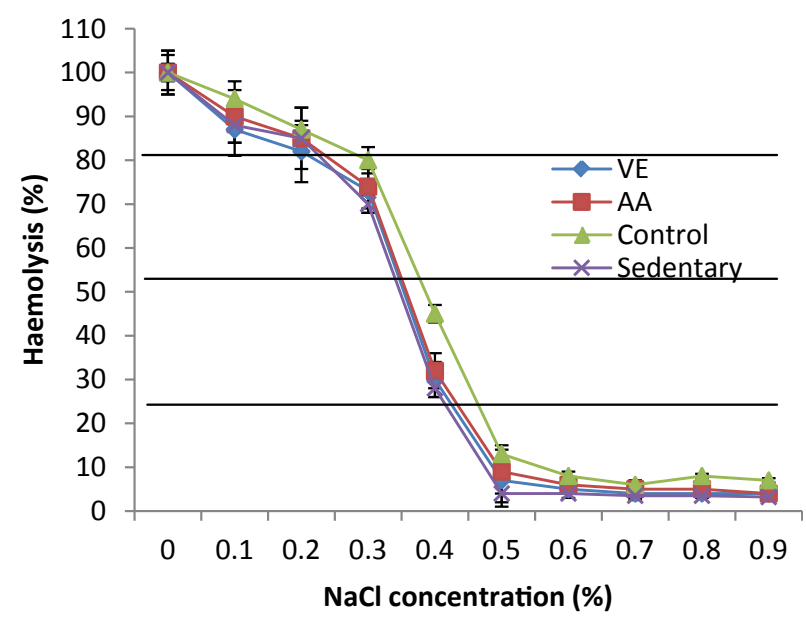

Figure 4: Effects of antioxidants vitamin $E$ and ascorbic acid on erythrocyte osmotic fragility of quails on day 7 of post-transportation recovery period.

in AA and control quails immediately, and 3 and 7 days after the transportation. The EOF recorded in AA quails immediately after transportation was lower than those recorded in the controlquails. After the transportation, values returned to base-line in AA on day 3; but in control quails, base-line values were attained only on day 7. Overall, the percentage erythrocytes that underwent $50 \%$ and maximum (80\%) haemolysis in the control quails at various $\mathrm{NaCl}$ concentrations immediately and 3 days after transportation were higher $(\mathrm{P}<0.05)$ than the pre-transportation values, and the corresponding values obtained in the erythrocytes of VE, AA and sedentary quails.

\section{Discussion}

Road transportation represents a critical phase in animal production and utilization and it is considered one of the main causes of stress. Such stress factors encountered during the transportation include handling and crating, noise and vibrations from the vehicle; emotional factors, such as unfamiliar transport environment; and climatic factors, such as high AT, RH and thermal load.During the study, the AT and $\mathrm{RH}$ recorded in the afternoon hours before transportation and inside the vehicle during the $2 \mathrm{~h}$ transportation period were above the upper critical values of $24^{\circ} \mathrm{C}$ and $64.3 \%$, respectively for quails [14,33]. Similarly, the THI was higher during the transportation and the afternoon hours, which suggested higher heat load on the birds. At this period, heat stress was apparent and posed a significant threat to the birds and, consequently, to their welfare. Thus, the high thermal load experienced by the birds compromised their thermoregulation and, consequently, cooling. The present result supports earlier findings that the hot-dry season in the study zone is thermally stressful to birds; and that it is characterised by high AT and high $\mathrm{RH}$, especially during the peak afternoon hours of the day [12,24]. Poultry raised or transported under such incremental environmental conditions have been reported to have high morbidity, mortality and low productivity $[12,14,24,33]$.

The CT recorded before transportation showed individual variation among the quails, and exhibited distinct diurnal fluctuations. Such fluctuations are normal, and they are driven by a biological clock in the brain [34]. The variations observed in CT were similar to the results obtained in pullets by Sinkalu and Ayo [35], who showed that CT fluctuates with AT and hour of the day. The mean CT value of $40.4 \pm$ $0.2^{\circ} \mathrm{C}$ recorded was within the recommended normal rage values of 40 $41.5^{\circ} \mathrm{C}$ for quails [36]. The increase above normal value in $\mathrm{CT}$, recorded 
Citation: Minka NS, Ayo JO (2013) Effects of Antioxidants Vitamin E and C on ErythrocyteFragility, HaemoglobinIndex and Colonic Temperature of Transported Japanese Quails (Coturnixcoturnix japonica). J Veterinar Sci Technol 4: 149. doi:10.4172/2157-7579.1000149

during the afternoon and evening periods indicates mild stress as a response of the body to accumulated heat load. Similar response of the body to heat load was reported in quails subjected to heat stress $[14,33,36]$. Although the increase in CT values recorded in sedentary quails, kept in cages under thermo-neutral AT and RH for two hours, was lower than that recorded in transported VE, AA and control quails, the values were above normal reference values. This finding suggested that crating of the quails even under thermo-neutral conditions may constitute a stress factor, and may induce acute hyperthermia, in quails raised in deep litter. Indeed, handling and crating of birds for whatever reason have been shown to constitute a major stressor during management of poultry $[12,23,24]$.

The significant increase in CT recorded in the control quails during the transportation period demonstrated the adverse effects of 2-h road transportation on the CT of the quails. The present result disagreed with that obtained by Tekelioglu et al. [2]; although the CT was not measured in the study, the result showed that $2 \mathrm{~h}$ of simulated transportation did not induce any stress in the quails. The difference in the finding of the present study and that of Tekelioglu et al. [2] may be due to the fact that the study was a simulation and the quails used were transported under thermoneutral AT of $18^{\circ} \mathrm{C}$.Such AT is not attainable under normal (natural) transportation conditions in tropical. However, the result of the present study agreed with that of González et al. [26], who demonstrated that road transportation of quails for $95 \mathrm{~min}$ under high $\mathrm{AT}$ of $45^{\circ} \mathrm{C}$ was very stressful. In general, poultry face difficulties in maintaining body temperature, especially under high ambient temperature, apparently due to lack of sweat glands and relatively high body temperature [37].

The CT values obtained in VE and AA quails after the transportation demonstrated the ameliorating effects of the antioxidants on CT of quails, subjected to road transportation stress under high AT, RH and THI. The antioxidant effect was more pronounced in VE quails as compared to AA quails, apparently because VE is a well-known lipophilic free-radical scavenger, mainly localised in phospholipid bilayer membranes [1]. This property of VE may contribute to its high efficacy in reducing $\mathrm{CT}$ of the quails than $\mathrm{AA}$, which is solely watersoluble and acts primarily in cellular fluid. Such high level efficacy of VE was not observed in pullets transported for 6 hours in the zone [12]. The reason for this difference may be due to variation in species and transportation duration. This requires further investigation.

The differential data, $\Delta \mathrm{CT}$, recorded in VE quails after transportation was not significantly different from pre-transportation data. The finding indicated that no significant adverse effects of the transportation and thermal stress were exerted on the CT of VE quails. Thus, VE mitigated the negative effects of road transportation- and thermal load-induced stress on CT of the quails. Similar result was also obtained in AA quails; although the magnitude of change in $\triangle \mathrm{CT}$ was higher $(\mathrm{P}<0.05)$ than that obtained in VE quails, but it was significantly lower $(\mathrm{P}<0.001)$ than the $\triangle \mathrm{CT}$ obtained in control quails. Both $\mathrm{VE}$ and $\mathrm{AA}$ are potent antioxidants that neutralise ROS generated during stress conditions, which were responsible for a series of pathological changes. Vitamins $\mathrm{E}$ and AA directly inhibit prostaglandin output, especially of PGE series, and cytokines, especially IL- 1 and IL- 6 , whose turn-over increases during stress. The cytokines are responsible for inflammation, a shift in thermoregulatory set-point and elevated body temperature $[38,39]$. Therefore, by affecting the thermoregulatory centre, the antioxidant vitamins apparently exerted ameliorating effects on the elevated CT in the transported quails. Furthermore, the fact that these vitamins are known to inhibit the release of cortisol $[40,42]$, the chief fear hormone, may be involved in the mechanism of regulation of the body responses, aimed at maintaining homeostasis. In addition, VE and AA have been reported to reduce heat load in birds $[12,14,16,21,43]$. Thus, the administration of the antioxidants pre-transportation reduced the adverse effects of incremental THI or heat load experienced by the birds inside the vehicle during the transportation period. Such high THI has been reported to induce hyperthermia and increase morbidity and mortality in transported broilers [44,45], pullets [12,15] and goats [25] subjected to road transportation under high environmental conditions.

The erythrocyte count and $\mathrm{Hb}$ concentrations, and the mean, minimum and maximum corpuscular fragility values recorded in quails before the transportation period were similar to the values recorded in healthy quails [30]. The AT and $\mathrm{RH}$ values recorded during the afternoon hours were considerably higher than the thermoneutral values. Such high AT and RH values did not induce significant adverse effects on the EOF. Similarly, the high CT values recorded in the afternoon hours in the quails did not have any significant effect on the erythrocytes. The result suggests that the increase in the AT, RH and CT values recorded before the transportation were not sufficient to increase significantly the damage to the erythrocyte membranes, apparently due to the short duration of exposure of the quails to the thermal environmental factors and, especially, their ability to adapt to such increment in AT and $\mathrm{RH}$.

The increase in erythrocyte count recorded after the transportation suggested that the transportation induced excitement, resulting in splenic contraction and the release of erythrocytes into the circulation. This mechanism is induced by the action of catecholamines on adrenergic receptors, located in the splenic capsule and partly attributed to a reduction in the plasma volume [8]. The higher $(\mathrm{P}<0.05)$ $\mathrm{Hb}$ concentration and EOF values obtained immediately, and 3and 7 days after transportation in the control quails as compared to VE and AA quails, indicates erythrocyte destruction due to the adverse effects of road transportation stress factors.Such stress factors were mainly handling, crating, vehicle motion and vibration, noise from the engine or moving vehicle, incremental micro-environmental conditions, travel sickness and novelty to the environment $[12,13,24]$. The stress factors in a complex way overtax the animal control systems and induce oxidative stress $[1,12]$.

The mechanism by which road transportation induced the increase in EOF in the quails may be multi-factorial.Firstly, the process of handling and crating and increase in muscular activities of the birds in the crates, as they attempt to escape or maintain balance, as well as the effect of vibration from the vehicle may result in mechanical trauma of the erythrocytes. Thus, the erythrocytes may be compressed against the blood capillaries within the contracting muscle leading to deformity and ultimate haemolysis [25]. Secondly, the elevated body temperature, due to thermal-load-induced stress experienced during the transportation, apparently "melt" the fatty acid tails of the phospholipid bilayer of the erythrocytes. The erythrocytes therefore, become more fluid and allow more movement and permeability of the cells, thereby damaging them. Furthermore, high temperatures recorded during transportation may cause proteins of the erythrocytes membrane to denature, which may lead to membrane disintegration and haemolysis $[7,10,25]$. Thirdly, transport-induced oxidative stress on erythrocytes due to the adverse effect of toxic ROS, presumably generated during the transportation, may also contribute to the deterioration of erythrocyte properties; leading to increase in haemolysis. This is true because the erythrocytes are susceptible to oxidative stress as a result of high contents of unsaturated fatty acids in their membranes [1]. The ROS may damage cell membranes of the erythrocytes in the transported quails by 
Citation: Minka NS, Ayo JO (2013) Effects of Antioxidants Vitamin E and C on ErythrocyteFragility, HaemoglobinIndex and Colonic Temperature of Transported Japanese Quails (Coturnixcoturnix japonica). J Veterinar Sci Technol 4: 149. doi:10.4172/2157-7579.1000149

Page 6 of 8

inducing lipid peroxidation of polyunsaturated fatty acids in their cell membranes. Furthermore, other factors, which were not measured in the present study, such as dehydration, haemoconcentration, depletion of $\mathrm{VE}$ and $\mathrm{AA}$, changes in blood $\mathrm{pH}$ and erythrocyte morphology, and increments in intracellular $\mathrm{Ca}^{2+}$ due to $\beta$-adrenergic stimulation, apparently as a result of acute exposure to transport-induce stress may cause erythrocyte deformability, and increase EOF and intravascular haemolysis [46].

The higher EOF, maintained 7 days after transportation in control quails, indicated the long-lasting adverse effects of transport-induced stress on the erythrocytes of the quails and that transportation may have profound effects on quails in ways that may not be immediately obvious. Thus, the amount of recovery time for quails that were transported for $2 \mathrm{~h}$ should be above 7 days before exploiting them further for meat, or research study. The duration should be considered as an important factor because oxidative stress does not exhibit immediate symptoms. Rather, it promotes the insurgence of serious pathologies as a result of degenerative damages of the cellular structure [5], which may adversely affect meat and egg quality or compromise research results.

The insignificant decrease in EOF values from the pretransportation values, recorded in VE quails immediately and 3 days after the transportation suggested that VE attenuated the damage on erythrocytes caused by the concomitant effects of heat and road transportation stresses. The stresses have been demonstrated to generate ROS, which induce lipid peroxidation of polyunsaturated fatty acids in membranes, and, consequently, destruction of cells. The mechanism by which VE attenuated EOF may be through decreasing lipid peroxidation and increasing intracellular antioxidant levels. This is particularly so because poultry cannot synthesize vitamin E. Therefore, the requirements of birds in the vitamin must be met from dietary sources. Thus, its supplementation during stressful conditions is of paramount importance. Vitamin $\mathrm{E}$ is known to be the most abundant fat-soluble and most efficient chain-breaking antioxidant available in the body, and is the primary defender against lipid peroxidation, maintaining cellular metabolic functions [22,47]. The lower EOF recorded in VE quails post-transportation as compared to AA and control quails further demonstrated the superior effect of VE over AA in combating transport-induced stress in quails.

The result of EOF recorded in AA quails immediately after transportation showed an increase above pre-transportation values, although the EOF value was lower than that recorded in control quails. The result also indicated the ameliorating effect of AA against transport-induced stress in erythrocytes of the quails. It is reasonable to assume that the administration of AA has reduced the intensity of oxidant stress, experienced by the quails during the transportation; apparently, by protecting both cytosolic and membrane components of erythrocytes from oxidant damage. In the cytosol, ascorbate acts as a primary antioxidant to scavenge ROS [48] that is presumably generated due to transportation-induced stress. For cellular membranes, AA may play an indirect antioxidant role in reducing the $\alpha$-tocopheroxyl radical to $\alpha$-tocopherol $[8,42]$, and probably recycles a-tocopherol in erythrocyte membranes and intact erythrocytes [42]. The erythrocyte results indicate that AA may interact directly with the plasma membrane as an antioxidant and also donate electrons to a trans-plasma membrane electron transfer activity in the erythrocytes [48]. On the overall, the result of the present study showed that road transportation of quails induced oxidative stress in the erythrocytes, resulting in increased osmotic fragility, which was ameliorated by VE and AA administration. Thus, EOF may be implored as a biomarker of oxidative and road transport-induced stresses in quails. The EOF may be added to the existing diagnostic tools, often used in the assessment of transport-induced stress.

The decrease in MCV and MCH recorded in the control quails below the normal values of 132.7 fland 44.0, respectively, established for quails [49], and pre- transportation values showed that stress due to road transportation decreased the volume and average $\mathrm{Hb}$ content in individual erythrocytes. The decrease in MCV indicates that older, stable and healthier erythrocytes were destroyed $[8,25]$, apparently due to the deleterious effects of the transport-induced stress. Higher MCV values are associated with larger, healthier and stable erythrocytes [50]. The results obtained in VE and AA quails, although at peak concentration levels, further demonstrated the protective role of the antioxidants, VE and AA on erythrocyte membranes. Similar results were reported in humans subjected to exhaustive exercises [8], and in goats pre-treated with AA and transported by road [25]. The significant increase in the value of MCHC in control quails after transportation confirmed the increase in $\mathrm{Hb}$ concentration, recorded in the controlquails.

The $\mathrm{Hb}$ index obtained in the control quails indicated that the transportation resulted in hypochromic erythrocytes; that is lower concentration of $\mathrm{Hb}$ in the individual erythrocytes. The result further demonstrated the low $\mathrm{Hb}$ concentration in the erythrocytes that were not fully haemolysed. However, the administration of antioxidants, VE and AA maintained the erythrocytes in a normochromic status, which suggested less cell damage. Smirnov et al. [32] and Minka and Ayo [25] showed that erythrocytes are normal (normochromic) if the $\mathrm{Hb}$ index is equal to one; hypochromic if less than one, which indicates a lower concentration of $\mathrm{Hb}$ in the erythrocytes; and hyperchromic, if higher than one.

In general, VE and AA have been shown to increase the activities of antioxidant enzymes, including glutathione peroxidase, SOD and CAT, towards the normal level, and decrease the levels of MDA, and the activities of serum biochemical activities [18,39,47]. Thus, the administration of VE and AA did not only ameliorate oxidative stress, but apparently, also enhanced the antioxidant status of the birds. Similar effects of VE and AA on the erythrocytes have been reported in humans, suffering from different diseases or subjected to strenuous exercise $[8,41,39]$, and in livestock, including poultry, subjected to diverse pharmacological and stressful conditions $[12,14,15,19,46]$. Of recent, the ameliorating effect of AA on the erythrocytes was shown in transported pigs [11,13] andgoats [24]. The result obtained in the present study on VE and AA clearly indicated the role of the antioxidant vitamins in maintaining erythrocyte membrane integrity and, consequently, decreasing the degree of haemolysis in transported quails. It is recommended that the antioxidants, VE and AA be administered prior to transportation for better management of road transportation stress in quail birds, especially during the hot-dry conditions.

\section{Conclusions}

Road transportation of quailsduring the hot-dry conditions induced hyperthermia, increased oxidative stress and EOF, which were attenuated by pre-treatment with antioxidants, VE and AA. The findings showed that recovery time duration after transportation in quails should be 7 days; but the duration may be eliminated if the quails are treated with $\mathrm{VE}$ or reduced to 3 days if treated with $\mathrm{AA}$, which suggested that the amelioration of road transport-induced stress was more effective in quails administered with VE as compared to those treated with AA. 
Citation: Minka NS, Ayo JO (2013) Effects of Antioxidants Vitamin E and C on ErythrocyteFragility, HaemoglobinIndex and Colonic Temperature of Transported Japanese Quails (Coturnixcoturnix japonica). J Veterinar Sci Technol 4: 149. doi:10.4172/2157-7579.1000149

\section{Ethical Standard}

All birds that served as subjects in this study were humanely cared for in accordance with the international guidelines governing poultry welfare during transportation by road $[51,52]$ and the research protocol was approved by the Departmental Research Committee on Animal Health and Husbandry, College of Agriculture and Animal Science, Division of Agricultural Colleges, Ahmadu Bello University, MandoKaduna, Nigeria.

\section{Acknowledgements}

The authors are grateful to the Laboratory staff of the College of Agriculture and Animal Science, Kaduna, and Mr E. N. Nwosu of the Department of Veterinary Physiology and Pharmacology, Ahmadu Bello University, Zaria, Nigeria for their technical assistance.

\section{References}

1. Altan O, PabuÃß̧cuoÄŸlu A, Altan A, KonyalioÄŸlu S, Bayraktar H (2003) Effect of heat stress on oxidative stress, lipid peroxidation and some stress parameters in broilers. Br PoultSci 44: 545-550.

2. Tekelioglu O, Sezer M, Ekici F, Atis O, Akbas A (2010) The effect of simulated transportation on biochemical plasma parameters of Japanese quails. J Anim Vet Advances 9: 892-895.

3. Casella S, Fazio F, Giannetto C, Giudice E, Piccione G (2012) Influence of transportation on serum concentrations of acute phase proteins in horse. Res Vet Sci 93: 914-917.

4. Piccione G, Casella S, Giannetto C, Giudice E, Fazio F (2012) Utility of acute phase proteins as biomarkers of transport stress in ewes. Small Rumin Res 107: 167-171.

5. Piccione G, Casella S, Giannetto C, Bazzano M, Giudice E, Fazio F (2013) Oxidative stress associated with road transportation in ewes. Small Rumin Res 112: $235-238$.

6. Giannetto C, Fazio F, Casella S, Marafioti S, Giudice E, et al. (2011) Acute phase protein response during road transportation and lairage at a slaughterhouse in feedlot beef cattle. J Vet Med Sci 73: 1531-1534.

7. Hanzawa K, Watanabe S (2000) Changes in osmotic fragility of erythrocytes in athletic horses. J Equine Sci 11: 51-61.

8. Tauler P, Aguiló A, Gimeno I, Fuentespina E, Tur JA, et al. (2003) Influence of vitamin $C$ diet supplementation on endogenous antioxidant defences during exhaustive exercise. Pflugers Arch 446: 658-664.

9. Oyewale JO (1992) Effects of temperature and $\mathrm{pH}$ on osmotic fragility of erythrocytes of the domestic fowl (Gallus domesticus) and guinea-fowl (Numidameleagris). Res Vet Sci 52: 1-4

10. Olaifa F, Ayo JO, Ambali SF, Rekwot PI (2012) Effect of packing on changes in erythrocyte osmotic fragility and malondialdehyde concentration in donkeys administered with ascorbic acid. Onderstepoort J Vet Res 79: E1-5.

11. Adenkola AY, Ayo JO, Sackey AKB, Adelaiye AB (2010) Erythrocyte osmotic fragility of pigs administered ascorbic acid and transported by road for shortterm duration during the harmattan season. Afr J Biotechnol 9: 226-233.

12. Minka NS, Ayo JO (2010a) Behavioural and rectal temperature responses of Black Harco pullets administered vitamin $C$ and $E$ and transported by road during the hot-dry season. J Vet Behav: ClinAppl Res 5:134-144.

13. Asala OO, Ayo JO, Rekwot PI, Minka NS, Omoniwa DO, et al. (2011) Effect of ascorbic acid administration on erythrocyte osmotic fragility of pigs transported by road during the hot-dry season. Vet Res Commun 35: 245-254

14. Sahin K, Onderci M, Gursu MF, Kucuk O, Sahin N (2004a) Effect of melatonin supplementation on biomakers of oxidative stress and serum vitamin and mineral concentrations in heat-stressed Japanese quail. J ApplPoult Res 13:342-348.

15. Minka NS, Ayo JO (2008) Haematology and behaviour of pullets transported by road and administered with ascorbic acid during the hot-dry season. Res Vet Sci 85: 389-393.

16. Minka NS, Adieza AA, Hassan FB, Ayo JO (2012) Effects of melatonin and transportation on rectal temperature, heterophil/lymphocyte ratio and behaviour of Japanese male quails (Coturnix japonica). NY Sci J 5: 52-59.
17. Naziroglu M, Sahin K, Simsek H, Aydilek N, Ertas ON (2000) The effects of food withdrawal and darkening on lipid peroxidation of laying hens in high ambient temperatures. DtschTierarztIWochenschr 107: 199-202.

18. Ohta Y, Yashiro K, Ohashi K, Imai Y (2012) Disruption of non-enzymatic antioxidant defense systems in the brain of rats with water-immersion restraint stress. J ClinBiochemNutr 51: 136-142.

19. Manjula KR, Subramanyam MV, Asha Devi S (2013) Protection against oxidative stress caused by intermittent cold exposure by combined supplementation with vitamin $E$ and $C$ in the aging rat hypothalamus. Neurochem Res 38: 876-885.

20. Voljc M, Frankic T, Levart A, Nemec M, Salobir J (2011) Evaluation of different vitamin $\mathrm{E}$ recommendations and bioactivity of a-tocopherol isomers in broiler nutrition by measuring oxidative stress in vivo and the oxidative stability of meat. PoultSci 90: 1478-1488.

21. Sahin K, Onderci M, Sahin N, Gursu MF, Kucuk O (2003) Dietary vitamin C and folic acid supplementation ameliorates the detrimental effects of heat stress in Japanese quail. J Nutr 133: 1882-1886.

22. Amazan D, Rey Al, Fernández E, López-Bote CJ (2012) Natural vitamin E (D-a-tocopherol) supplementation in drinking water prevents oxidative stress in weaned piglets. LivestSci 145: 55-62.

23. Freeman BM, Kettlewell PJ, Manning AC, Berry PS (1984) Stress of transportation for broilers. Vet Rec 114: 286-287.

24. Minka NS, Ayo JO (2008) Assessment of the stresses imposed on adult ostriches (Struthiocamelus) during handling, loading, transportation and unloading. Vet Rec 162: 846-851.

25. Minka NS, Ayo JO (2010) Physiological responses of erythrocytes of goats to transportation and the mondulatory role of ascorbic acid. J Vet Med Sci 72 875-881.

26. González VA, Rojas GE, Aguilera AE, Flores-Peinado SC, Lemus-Flores C et al. (2007) Effect of heat stress during transport and rest before slaughter on the metabolic profile, blood gases and meat quality of quail. Int $\mathrm{J}$ PoultSc 6: 397-402.

27. Steadman RG (1984) A universal scale of apparent temperature. J Appl Met 23:1674

28. Abdel-Azeem FA (2010) The influence of different stocking density and sex on productive performance and some physiological traits of Japanese quail. Egypt PoultSci 30:203-227

29. Beutler W (1986) Osmotic fragility. In: Williams WJ, Bultler E, Erslev AJ Lichtman MA (Eds), Haematology. McGraw-Hill, New York, USA.

30. Viscor G, Palomeque J (1982) Method of determining the osmotic fragility curves of erythrocytes in birds. Lab Anim 16: 48-50.

31. Schalm OW, Jain NC, Carroll EJ (1975) Veterinary Haematology(3rd Edn) Lea and Ferbger, Philidelphia.

32. Smirnov AM, Konopelko PY, Pushkov SP, Postnikov VS, Urazav NA, et al. (1987) Methods of clinical examination. In: Smirnov AM (Eds), Internal Noninfectious Diseases of Animals. Kolos Press, Moscow (in Russian).

33. Sahin N, Onderci M, Sahin K, Gursu MF, Smith MO (2004) Ascorbic acid and melatonin reduce heat-induced performance inhibition and oxidative stress in Japanese quails. Br PoultSci 45: 116-122.

34. Piccione G, Caola G (2002) Biological rhythm in livestock. J Vet Sci 3: 145-157.

35. Sinkalu VO, Ayo JO (2009) Modulatory Role of Vitamin A on Individual and Diurnal Fluctuations in Rectal Temperature of Black Harco Pullets. Intern J Appl Res Vet Med 7:103-111.

36. Woodard AE, Mather FB (1964) Effect of photoperiod on cyclic patterns of bodytemperature in the quail. Nature 203: $422-423$

37. Donkoh A (1989) Ambient temperature: a factor affecting performance and physiological response of broiler chickens. Int J Biometeorol 33: 259-265.

38. Piccione G, Fazio F, Giannetto C, Assenza A, Caola G (2007) Oxidative stress in thoroughbreds during official 1800-meter races. Vet Arhiv 77:219-227.

39. Nazrun AS, Norazlina M, Norliza M, Nirwana SI (2012) The anti-inflammatory role of vitamin e in prevention of osteoporosis. AdvPharmacolSci 2012: 142702

40. Karanth S, Yu WH, Walczewska A, Mastronardi C, McCann SM (2000) Ascorbic acid acts as an inhibitory transmitter in the hypothalamus to inhibit stimulated luteinizing hormone-releasing hormone release by scavenging nitric oxide. ProcNatlAcadSci U S A 97: 1891-1896.

41. Balz F (2003) Vitamin C intake. Nutr Dis 14:1-18 
Citation: Minka NS, Ayo JO (2013) Effects of Antioxidants Vitamin E and C on ErythrocyteFragility, HaemoglobinIndex and Colonic Temperature of Transported Japanese Quails (Coturnixcoturnix japonica). J Veterinar Sci Technol 4: 149. doi:10.4172/2157-7579.1000149

42. Powers SK, Jackson MJ (2008) Exercise-induced oxidative stress: cellular mechanisms and impact on muscle force production. Physiol Rev 88: 12431276.

43. Pardue SL, Thaxton JP, Brake J (1984) Plasma ascorbic acid concentration following ascorbic acid loading in chicks. PoultSci 63: 2492-2496.

44. Mitchell MA, Kettlewell PJ, Maxwell MH (1992) Indicators of physiological stress in broiler chickens during road transportation. AnimWelf 1:91-103.

45. Mitchell MA, Kettwell P (1994) Road transportation of broiler chickens: induction of physiological stress. World's PoultSci J 50:57-59.

46. Sentürk UK, Gündüz F, Kuru O, Aktekin MR, Kipmen D, et al. (2001) Exerciseinduced oxidative stress affects erythrocytes in sedentary rats but not exercisetrained rats. J ApplPhysiol (1985) 91: 1999-2004.

47. Ambali SF, Ayo JO, Ojo SA, Esievo KA (2010) Vitamin E protects Wistar rats from chlorpyrifos-induced increase in erythrocyte osmotic fragility. Food ChemToxicol 48: 3477-3480.
48. May JM (1999) Is ascorbic acid an antioxidant for the plasma membrane? FASEB J 13: 995-1006.

49. Durai PC, Maruthai RPT, Arumugam SS, Venugopal OA (2012) Haematologica profile and erythrocyte indices in different breeds of poultry. Int J Lives Res 2 :89-92.

50. Seibert CS, Guerra-Shinohara EM, Carvalho EG, Marques EE (2001) Red blood cell parameter and osmotic fragility curve of Colossomamacropomum (Pisces, Osteicthyes, Mileinae) in captivity. ActaSci 23:515-520.

51. European Food Safety Authority (EFSA) (2004) Opinion of the Scientific Pane on Animal Health and Welfare on a report from the Commission related to the welfare of animals during transport

52. Royal Society for the Prevention of Cruelty to Animals (RSPCA) (2011) Quail: Good practice for housing and care. Research Animals Department (4th Edn). West Sussex RHI3 9RS. 